\title{
A new computer application for innovation and evaluation in counseling
}

\author{
James Ayers ${ }^{* 1}$, William Schmidt ${ }^{1}$, Michael W Ross ${ }^{2}$, Thomas W Bugbee ${ }^{1}$, and Joan Knight ${ }^{1}$ \\ ${ }^{1}$ UfaceME, Inc., Minneapolis, MN, USA \\ ${ }^{2}$ Department of Family Medicine, University of Minnesota Medical School, Minneapolis, MN, USA
}

\begin{tabular}{l}
\hline Article Info \\
\hline Article history: \\
Received Feb $25^{\text {th }}, 2021$ \\
Revised Mar $20^{\text {th }}, 2021$ \\
Accepted Apr $10^{\text {th }}, 2021$ \\
\hline
\end{tabular}

\section{Keyword:}

counseling feedback, computer application, counselor rating, client rating, interpersonal

\begin{abstract}
To measure the effect of counselling, outcome measures are obtained after completion of a counseling session because measuring outcomes and changes that occur during and within the counseling session itself is problematic. This problem was addressed by a new method demonstrated with medical students. ${ }^{1}$ Rarely has a counseling session been documented by clients. ${ }^{2}$ Using the UfaceME ${ }^{\circledR}$ method, Clients or people acting as clients responded to a series of statements which were repeated every four minutes as they watched video-audio replay of their session. They then observed by viewing and rating a comparison of their responses with those of their counselor. This study shows the benefits of the UfaceME method as an application to measure change that occurs within a counseling session. Significant positive changes were demonstrated in clients' perception and feelings towards the end of the session compared to the beginning. Implications and results to date include further counseling engagement, healthy behavioral and relational change, improved mental health, and improved selfawareness.
\end{abstract}

C 2021 The Authors. Published by Redwhitepress.

This is an open access article under the CC BY-NC-SA license

(https://creativecommons.org/licenses/by-nc-sa/4.0/

\section{Corresponding Author:}

James Ayers

UfaceME, Inc., Minneapolis, MN, USA

Email: ayersjames@gmail.com

\section{Introduction}

What makes counseling work? How and when is therapeutic effectiveness measured? And by whom? Historically, this has been documented by the counselor in case notes, subjective impressions, and after-thefact recollections. Typically, the client has not also rated the process and their feelings at the same time and using the same rating format as the counselor, to enable both to observe and rate the encounter. We describe a 
new computer application which allows both counsellor and client to observe and rate their perception of the counseling process, using the same constructs, and compare the perception of the counselor with that of the client. Thus, the process, and significant moments, can be highlighted and discussed.

\section{The UfaceME® counseling training method}

The UfaceME method evolved from the Interpersonal Process Recall method (IPR) 3 developed by Kagan3 to use audio video playback of a face-to-face conversation to stimulate recall by the participants who stop the playback when they remember something and verbalize subjective experiences that the camera did not record. The IPR recall/reporting process is spontaneous and unstructured. The UfaceME method, operating on a laptop computer, uniquely structures the recall/reporting process by having participants watch the playback nonstop while at the same time they respond to a series of statements which are repeated at preset intervals. In this way participants quantify or code their qualitative experiences into a personalized database which allows analysis and graphic feedback to both participants. The content and structure of the statements were developed from theories and research in various disciplines including social psychology, applied counseling psychology, interpersonal learning theories, and assessment methodologies.4, 5, 6

In this current study utilizing UfaceME, a single, white male counselor had 161 conversations in counseling, supervision and consultation settings which were recorded. Both counselor and the other person then responded simultaneously and independently to identical statements about how they were feeling from three perspectives: how they viewed themselves, the other person, and how they thought they were being viewed by the other person. These three viewpoints are called Self view, Other view, and Social view respectively. Sixteen statements (as shown in Table 1) were presented sequentially every fifteen seconds to comprise a complete series of four-minutes, after which the series was repeated until the end of the counseling session. This arrangement allowed comparison between the first and last four-minutes of the session. Participants responded on a small keypad to each statement on a five-point Likert scale: 1 Not at all, 2 A little, 3 Moderately, 4 Quite a bit, 5 Very much. Responses were stored on a laptop computer for analysis and graphic feedback.

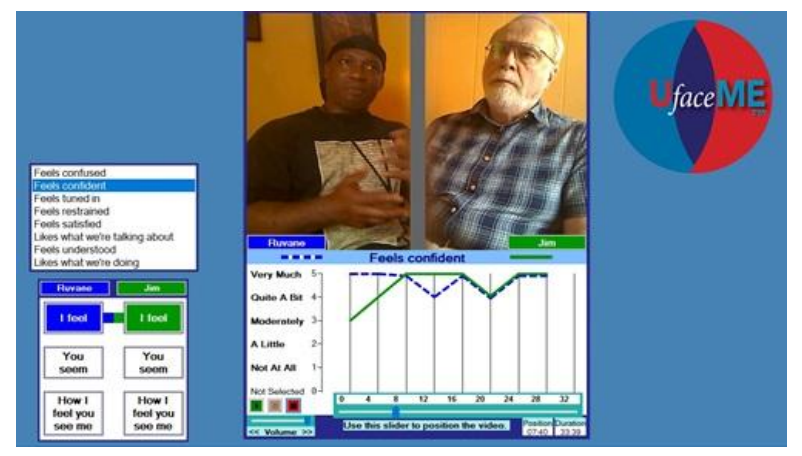

Figure $1<$ Graphic Feedback Display after a UfaceME Conversation $>$

The subjects of this study were 161 individuals who met with the same counselor for a single UfaceME session lasting at least sixteen minutes. They were 118 actual clients engaged in counseling, 26 graduate students in supervision, and 17 colleagues in consultation with the counselor. Client demographics: female (32), male (129); ethnicity: White (85), Black (64), Asian-American (4), Hispanic (4), Native-American (4. The average age of subjects was 41.3 years. The sessions took place over a five-year period at different substance abuse and counseling settings. The counselor was a white doctoral-trained clinical psychologist with over 40 years of experience. The sixteen statements and their order of presentation for each series are displayed in Table 1 where results for the first and last four-minutes of the counseling session are presented and compared for significance with a one-sided $t$ test. The response ratings were $1=$ Not at all and $5=$ Very much. The ANOVA analysis is from Microsoft Excel spreadsheet. 
A new computer application for innovation...

Table $1<$ Mean Ratings for First and Last Four Minutes and Differences $>$

\begin{tabular}{llccc}
\hline Statement & First 4 Min & Last 4 Min & Difference & P value \\
\hline I feel Confident & 3.746 & 3.780 & 0.340 & 0.413 \\
\hline I see you feeling Confident & 4.178 & 4.185 & 0.070 & 0.478 \\
\hline $\begin{array}{l}\text { I think you see me as } \\
\text { Confident }\end{array}$ & 3.466 & 3.720 & 0.254 & ${ }^{*} 0.0267$ \\
\hline I feel Satisfied & 3.292 & 3.913 & 0.621 & ${ }^{*} 0.0000378$ \\
\hline I feel Confused & 1.981 & 1.839 & -0.142 & 0.158 \\
\hline I see you feeling Confused & 1.702 & 1.627 & -0.750 & 0.280 \\
\hline $\begin{array}{l}\text { I think you see me feeling } \\
\text { Confused }\end{array}$ & 1.845 & 1.876 & 0.031 & 0.407 \\
\hline I feel Connected & 3.801 & & & \\
\hline I feel Tuned In & 4.090 & 4.075 & 0.274 & 0.132 \\
\hline I see you feeling Tuned In & 4.242 & 4.220 & 0.130 & 0.267 \\
\hline $\begin{array}{l}\text { I think you see me feeling } \\
\text { Tuned In }\end{array}$ & 4.099 & 4.317 & 0.075 & 0.310 \\
\hline I feel Understood & 4.118 & 4.155 & 0.056 & 0.070 \\
\hline I feel Restrained & 1.705 & 4.286 & 0.168 & \\
\hline I see you feeling Restrained & 1.932 & 1.603 & -0.102 & 0.050 \\
\hline $\begin{array}{l}\text { I think you see me feeling } \\
\text { Restrained }\end{array}$ & 2.075 & 1.752 & -0.180 & 0.183 \\
\hline I feel Calm & 1.950 & -0.125 & 0.432 \\
\hline An asterisk next to P values indicates statistical significance at p<.05.
\end{tabular}

This initial report focuses only on the various subject's experience. A comparison of the averages between the first and last four minutes for fifteen of the sixteen statements showed a change in a positive direction. The results for four statements were statistically significant: satisfaction, feeling that they were viewed by the counselor as more confident, feeling more connected, and feeling less restrained. Part of this can be attributed to the skill of the counselor which is a constant for all the sessions. But counseling is an interactive process where both client and counselor are factors, dependent on their ability to work together in a process that is measured immediately after their session.

\section{Discussion}

This study combined all subjects from three distinct settings (counseling, supervision, and consultation) in order to assess change over an eight-minute period in the middle of a sixteen-minute conversation. The structured recall/response with repeated series of statements employed in the UfaceME method provides quantitative data synchronized with the video recording. This provides data generated by each participant, which can be analyzed and shared without disclosing the identity of participants. It provides empirical data describing results of each UfaceME session as well as how, when, and by whom it happens, providing a better understanding of the interactive process itself. The subjects of this study were in actual counseling settings versus a laboratory setting. This bridges clinical research with clinical practice which Kazdin has stressed as the greatest need to improve client care. ${ }^{7}$

The results of this study demonstrate several things about the UfaceME method. It is a practical, userfriendly tool that can be used in various settings with diverse clients and contexts. It equally engages both client and counselor in coding their qualitative experience into quantitative measures to generate a database which can be analyzed in various ways. The method appears to incentivize people to engage more directly with each other face-to-face, possibly out of curiosity, because they expect to see for themselves, measure how they came across to each other and get immediate graphic feedback which they can discuss in some detail. All subjects participated voluntarily and gave informed consent after a brief description of the UfaceME method. 
It is noteworthy that no one refused to have a UfaceME conversation. Examples of client comments are "It was helpful to perceive how other people see me. It gives me motivation to stay open, to not close myself off from people because of the way I perceive them to be perceiving me." "That process facilitated in me a comfort level. I feel better because of it." Empirical research has demonstrated the effectiveness of various counseling methods and techniques, especially the importance of establishing a therapeutic alliance between counselor and client. ${ }^{7}$ This happens when clients experience an increase in satisfaction, feeling connected, being viewed as more confident, and feeling less restrained in the counseling session itself as is demonstrated by the statistical significance of the client's responses. While the aggregate data of subjects in three distinct settings showed positive changes, a separate analysis of the 118 counseling together with the counselor could lay the groundwork for establishing an empirical methodology to note client and counselor changes relevant to understanding how establishment of a therapeutic alliance impacts counseling effectiveness.

\section{Disclosures for this paper}

Dr. Ayers, Mr. Schmidt, Mr. Bugbee, and Ms. Knight are UfaceME Co-Founders and report conflict of interest. In addition, Dr. James Ayers was the counselor in this study and reports he is CEO of UfaceME, Inc. and has a patent 9099010 issued, a patent 9262539 issued, a patent 9571753 issued, and a patent 9832392 issued; The patents are assigned to UfaceME, Inc. Mr. William Schmidt reports he is VP of Technology of UfaceME, Inc. and is named in the same patents as Dr. Ayers. Mr. Thomas W. Bugbee reports he is the COO \& CFO of UfaceME, Inc. Ms. Joan Knight reports she is VP of Marketing of UfaceME, Inc. Dr. Michael Ross reports no conflicts of interest in this work.

\section{References}

Ross MW, Ayers J, Schmidt W, Bugbee TW, Knight J, Muthyala BK, Newstrom NP. A new computer application for teaching sexual history taking to medical students: innovation and evaluation in the UfaceME ${ }^{T M}$ program. Adv Med Educ Pract. 2019;10:333-341. https://doi.org/10.2147/AMEP.S1954611

Miller SD, Hubble MA, Chow D, Seidel J. (2015). Beyond measures and monitoring: Realizing the potential of feedback-informed treatment. Psychotherapy, 2015, Vol. 52, No. 4, 449-457.http://dx.doi.org/10.1037/

Kagan N. (1980). Influencing human interaction - Eighteen years with IPR. In A.K. Hess (Ed.), Psychotherapy supervision: Theory, research, and practice (pp. 262-283). New York: Wiley.

Laing RD, Phillipson H, Lee AR. (1966). Interpersonal perception: a theory and a method of research. London: Harper and Row.

Ayers J. (1980). A preliminary report on the empirical assessment of face-to-face Interaction by means of structured video stimulated recall: The Interpersonal Tracking Task. (unpublished manuscript). Department of Psychology. University of Minnesota).

Ayers J. (2009). Ten reasons why we psychologists don't observe our face-to-face work... and what difference it makes. Minnesota Psychologist, November, 2009.

Kazdin AE. (2008). Evidence-based treatment and practice: New opportunities to bridge clinical research and practice, enhance the knowledge base, and improve patient care. American Psychologist, 63, pp 146-159. 